\title{
Para quién escribimos. Circular, producir, cambiar de lengua
}

• ANNICK Louis / Université de Reims - CRAL / EHESs / CNRS / alouis@noos.fr

\section{Resumen}

El presente artículo presenta una reflexión sobre la inscripción del público en los escritos de los investigadores en ciencias humanas y sociales, y en particular de los especialistas de literatura, en el caso de quienes se desplazan entre dos comunidades intelectuales, la argentina y la francesa. El objetivo es pensar las posiciones críticas de quienes se dirigen a varios públicos simultáneamente.

Palabras clave: comunidades intelectuales • escritura y público $\cdot$ Argentina $\cdot$ Francia $\cdot$ estudios literarios

\section{Abstract}

This paper studies the inscription of the readers in the papers and research of academics working in human and social sciences, particularly the case of those specialized on literature that coming from Latin Americanemigrate to France. The goal is to understand the critical position determined by the fact that they address to at least different readers.

Key words: intelectual communities $\cdot$ critic writing and readership $\cdot$ Argentina $\cdot$ France $\cdot$ literary studies
Panesi nos llama «los que se fueron». ${ }^{1}$ En la historia intelectual argentina, la categoría se aplica tanto a escritores como a críticos, y suele oponerse a la de «los que se quedaron», aunque en verdad habría que tener en cuenta una tercera: «los que volvieron». ${ }^{2}$ Para quienes nos fuimos, el proceso de búsqueda de un público lector para nuestros trabajos críticos es radicalmente diferente de lo que hubiera sido de habernos quedado. Quisiera proponer aquí unas reflexiones sobre el público al que destinamos, o creemos destinar, nuestros trabajos algunos de los críticos que nos fuimos. En mi caso particular el desplazamiento se produjo entre Buenos Aires y París. ${ }^{3} \mathrm{Su}$ particularidad viene del hecho de que los intelectuales argentinos estamos familiarizados con las producciones francesas, pero ignoramos generalmente el funcionamiento académico del país y sus especificidades. Por lo tanto, nos encontramos al desplazarnos a Francia con una realidad institucional
Fecha de recepción: I/06/2016 Fecha de aceptación: $30 / 07 / 2016$ 
totalmente desconocida. Si asistimos actualmente a una internacionalización de los saberes, las topografías académicas siguen siendo nacionales, y dependen de una historia y una tradición específicas.

Lo más probable es que los factores esenciales para pensar las carreras de los intelectuales que se desplazan de una comunidad intelectual a otra sean el momento de la carrera en que se produce el desplazamiento, y la razón por la que se decide irse. En cuanto al primero, las condiciones de inserción dependen efectivamente en gran medida de si se han terminado los estudios universitarios o no, si se está en el comienzo de la carrera, entre la licenciatura y la maestría, o si, como en algunos casos, investigadores reconocidos buscan un empleo académico en otro país. Este último caso es particular, porque no hay entonces loss of readership; ${ }^{4}$ aunque las condiciones de producción cambien, se conservan lectores, y a éstos se van a sumar otros, en la nueva comunidad. Si el momento en que se emigra es un factor determinante en la inserción profesional es porque la densidad y perdurabilidad de las redes construidas previamente depende en parte del desarrollo de la carrera en el propio país; las pertenencias institucionales y las relaciones personales permiten a los investigadores ir construyendo un círculo de lectores-interlocutores en su propia comunidad. Pero al desplazarse hacia otra se debe empezar un nuevo proceso, dentro de una comunidad con reglas y modos de funcionamiento distintos, que lleva tiempo comprender, lo cual produce a menudo la impresión de volver a empezar.

Si el desplazamiento se realiza en los comienzos de la carrera, que es lo más habitual, por ejemplo entre la licenciatura y la maestría (es más fácil y común emigrar con un primer diploma), se ve uno confrontado a un momento durante el cual se tiene la impresión de no tener público: se ha perdido lo poco que se logró (puesto que todos los estudiantes participan en congresos y publican artículos durante sus estudios), y aún no se ha construido una red que permita dar a conocer sus trabajos en la nueva comunidad. Este momento, que la dinámica académica actual suele reducir en duración, puede resultar difícil y solitario; pero es necesario pasarlo, sin ceder a la angustia que provoca, y sin tratar de conservar a toda costa lo que se tenía (si se puede, es una buena cosa, pero suele ser difícil), porque es una etapa de silencio esencial en el traspaso entre comunidades. Personalmente, no logré conservar como interlocutores a quienes fueron mis compañeros de estudio más cercanos, pero fui construyendo con el tiempo vínculos intensos de intercambio con intelectuales de otras generaciones, y con algunos de mi propia generación que no frecuentaba en tanto estudiante.

En cuanto a las razones por las cuales los intelectuales se desplazan, el factor esencial es probablemente si la decisión es personal o si responde a una razón externa, porque, aunque se hable poco de ello, el "por qué uno se va» se inscribe en el desarrollo posterior de la carrera, y marca los comportamientos dentro de la comunidad intelectual, en especial cuando, una vez establecidos, empezamos a ver llegar y a recibir a las nuevas generaciones (es sabido: tenemos tendencia a imponer nuestros propios recorridos, en particular si nuestras elecciones han 
sido coronadas de éxito institucional). Entre los estímulos externos se cuentan, por supuesto, las razones políticas, que obligaron a varias generaciones de intelectuales hispanoamericanos a emigrar; pero hay que tener en cuenta también las sucesivas crisis económicas y, hasta hace unos diez o quince años en Argentina, la falta de una estructura académica sólida, que permitiera una profesionalización satisfactoria. Sin embargo, un factor externo puede ser también personal, como la decisión de seguir a alguien (padres, pareja). En cambio, quienes hemos tomado la decisión de irnos por motivos de orden intelectual, lo hicimos en función de un proyecto académico y/o personal propio - aunque como dice Claudio Canaparo, somos muchos los que creemos habernos ido por decisión personal cuando en verdad había probablemente razones sociales (él y yo pertenecemos a la generación que emigró en el momento de los levantamientos populares del comienzo de los ańos i990).

Si el "por qué nos fuimos» es importante en relación con el público para el que escribimos es porque los estímulos externos a menudo impiden elegir el momento ideal para el desplazamiento y preparar redes y contactos antes de hacerlo, de modo de poder seguir contando con lectores e interlocutores durante los primeros tiempos en que se está afuera. Las partidas precipitadas no favorecen la preparación de la inserción, aunque en algunos casos las dificultades del comienzo pueden ser compensadas por la creación de alianzas eficaces en el país de adopción, y llevar a carreras exitosas.

Respecto de la circulación de investigadores entre Argentina y Francia, para comprender para quién escribimos hay que tener en cuenta otro factor: la lengua. Se trata, en efecto, de un desplazamiento que implica comenzar a escribir en otro idioma, además del propio, y del dominio del francés depende también la calidad de la inserción; un caso especial somos, sin embargo, los que tenemos la suerte de ser bilingües: para nosotros el cambio de lengua tiene significados diferentes, en mi caso pasar al francés para los trabajos académicos sonó (misteriosamente) el fin de mis dificultades para escribir y producir. Pero (también extrañamente) introdujo una suerte de proscripción de toda inscripción visible de lo personal: la pasión se objetivó y estructuró. Cada situación demanda una elección entre español o francés, parámetro que va a modificar al público lector potencial. Para los trabajos institucionales, se impone generalmente la lengua del país; pero conozco por lo menos un caso de tesis redactada en francés, y que nunca fue publicada, en parte por la dificultad de resolver la cuestión de la lengua en que debía serlo. Fuera de esto, en muchas ocasiones se nos pide que escribamos en una de las dos lenguas, pero a menudo la elección es nuestra, en especial en proyectos y trabajos que resultan de iniciativas personales, y en ese caso sí el público deseado juega un papel importante en la elección del idioma (volveré sobre esta cuestión).

A partir de estas consideraciones podemos identificar varias situaciones de carrera, que determinan respuestas diferentes a la pregunta ¿para quién escribimos?

Un primer caso lo constituyen los investigadores de origen argentino, formados en el sistema académico francés, y que trabajan en éste; sus carreras se desa- 
rrollaron esencialmente en Francia, generalmente se trata de personas que emigraron antes de la formación universitaria. Aunque publican en los dos idiomas, la orientación epistemológica de sus trabajos está marcada por las tendencias interpretativas y metodológicas de la academia francesa, una formación completada por supuesto con lecturas que vienen de otras comunidades especializadas. Estos investigadores circulan esencialmente entre comunidades de su área cultural, en Francia y los países donde el hispanismo está representado, ya sea los Estados Unidos o Europa; el uso del español permite participar de eventos internacionales que tratan del objeto de estudio, es decir, diferentes aspectos de la cultura hispanoamericana. ¿Quién es el público de estos investigadores? Esencialmente la red de colegas del hispanismo francés, y eventualmente los colegas que se especializan en los mismos temas que ellos que pertenecen al hispanismo internacional. En este caso, la elección del idioma determina en parte la circulación de los trabajos, porque el español permite salir de la red nacional, y permanecer entre especialistas del hispanismo.

Un segundo caso es el de los investigadores que se formaron en parte en la institución argentina (o en la de otro país hispanoamericano), que se insertan en la francesa en diferentes momentos - maestría, doctorado- y trabajan actualmente en ella. La inserción demanda por supuesto un buen conocimiento de la lengua, que permite luego producir en español o en francés; por otro lado, antes de partir, generalmente han tenido la oportunidad de comenzar a publicar sus trabajos, y pueden conservar (en parte) sus redes al emigrar, permitiendo también así una mejor comunicación entre ambas comunidades. Sin embargo, al haber sido formados, aunque más no sea parcialmente, en su país de origen, estos investigadores se encuentran en una situación particular al emigrar; llegan con una tradición interpretativa y retórica distinta de la francesa, que no solamente no es conocida o reconocida en Francia, sino que puede ser necesario abandonar para poder adoptar los modos y usos de la academia local. Se encuentran así confrontados a un conflicto de valores: si adoptan los valores intelectuales, los métodos, los modos de producción de la academia francesa, se produce una mejor inserción académica, pero se alejan de su formación primera. Paradójicamente, la crítica argentina tiene un gran prestigio entre los especialistas franceses, pero la inserción demanda que quienes están en formación abandonen esa tradición y adopten los modos y métodos de trabajo nacionales.

Como es sabido, la topografía académica francesa presenta varias particularidades que permiten explicar en parte la orientación de los estudios literarios. En primer lugar, la división del sector terciario entre grandes escuelas y universidad, que determina que las elites culturales y políticas vengan de las grandes escuelas, espacio donde cada uno constituye sus redes y sus garantías de carrera. Por otro lado, es determinante la orientación de la universidad hacia los denominados concursos: la Agregación ${ }^{5}$ y el CAPEs, ${ }^{6}$ que imponen un modo de enseñanza y una aproximación de los saberes específicos; el tratamiento del texto literario no corresponde a la perspectiva de la investigación, y tampoco a la formación en 
Letras de las universidades latinoamericanas. Por eso en el caso de los intelectuales formados en Argentina que van a Francia y deciden adoptar sus modos de producción y su sistema académico, el desplazamiento de un país a otro implica un renunciamiento, y a menudo un cambio de disciplina, necesarios para lograr una buena inserción institucional.

Esta situación no deja de ser paradojal: muchos intelectuales argentinos e hispanoamericanos en general, vienen a Francia atraídos por la tradición teórica francesa; sin embargo, el recorte disciplinario y académico del país, la importancia que tienen las redes y los sistemas de certificación nacionales, los obligan generalmente a refugiarse en el hispanismo - es decir en una disciplina que no existe en sus países de origen, que es generalmente menos teórica que los estudios de Letras (en Argentina al menos), y cuyas bases epistemológicas les resultan poco concretas porque fueron formados dentro de la óptica de las literaturas nacionales-. Se ven así obligados a renunciar a una parte de sus ambiciones intelectuales, y a cambiar de disciplina, lo que limita también la elección de los objetos sobre los cuales van a trabajar. Notemos, sin embargo, que muchos de estos intelectuales formados en las Letras - es decir en una perspectiva más interdisciplinaria que en Francia- tenían la intención de especializarse en el estudio de la literatura argentina, por lo cual no siempre tienen que renunciar a su objeto de estudio, sino simplemente ampliarlo y cambiar la metodología de trabajo. Aunque ser un «hispanista» que trabaja en Europa o Estados Unidos, corresponda a una identidad totalmente diferente de la que se define cuando en su propio país uno se dedica a estudiar la literatura nacional o latinoamericana.

A pesar de esto, podemos decir que hay aquí una doble pérdida: investigadores cuya formación les permitiría establecer un diálogo productivo con comunidades nacionales de filósofos, teóricos, etc., se ven privados de esta oportunidad porque la única inserción que se abre a ellos tiene por base el manejo de la lengua y de la cultura hispánicas; las comunidades francesas pierden también la oportunidad de dialogar con investigadores que vienen de otras tradiciones intelectuales pero que conocen y dominan la suya. Una doble pérdida que se debe en parte a la existencia de recortes disciplinarios e institucionales diferentes en cada país, pero también al uso de la lengua; porque a menudo estos intelectuales eligen, precisamente para conservar el diálogo con su comunidad de origen, continuar escribiendo y publicando en español, de modo de hacer circular sus trabajos entre la comunidad hispanista internacional, y en especial entre los colegas de la comunidad de la que vienen. Puede decirse que se trata de un movimiento dialéctico: se elige el español porque de todos modos los trabajos tienen muy pocas chances de ser integrados en el circuito intelectual nacional francés, y porque se escribe en español se excluye todo diálogo posible. La elección de la lengua muestra, entonces, generalmente, la orientación del crítico: si se elige el español, es porque se mantienen los intereses intelectuales de la formación primera, y si se privilegia el francés es para afianzar la integración en el sistema adoptado profesionalmente. Los primeros permanecen presentes en sus comunidades de origen, pero, como 
decíamos, se vuelve difícil o imposible el diálogo con especialistas de otras áreas culturales y de otras especialidades; en el segundo caso, tampoco se sale necesariamente del círculo hispanista local, pero se acentúa el funcionamiento académico.

Existe, sin embargo, otro modo de integrar la nueva comunidad que define un público diferente para nuestros escritos al cual quisiera referirme puntualmente puesto que se trata de mi propia elección. Algunos investigadores formados en parte en Argentina que se insertan en Francia en momentos diferentes de sus carreras, eligen (elegimos) tratar de salir del círculo hispanista y establecer un diálogo con otras comunidades disciplinarias francesas no especializadas en la literatura y la cultura latinoamericanas, conservando, al mismo tiempo, vínculos con el país de origen. Esta posición implica la producción de objetos en función de parámetros e intereses intelectuales distintos de los dominantes en el hispanismo y, sobre todo, impone el trabajo en lengua francesa; los medios de publicación también determinan normas discursivas e intelectuales distintas, por lo que el resultado de estas producciones es que suelen combinar tradiciones interpretativas.

La elección del objeto y de la lengua están, por lo tanto, estrechamente vinculados, aunque la lógica a que responden sea difícil de comprender; la relación entre objetos, lectores y lengua es a menudo menos coherente de lo que creemos, porque las razones que llevan a escribir un texto en una lengua pueden ser meramente circunstanciales; resulta por momentos de estrategias de carrera, otras del azar, a veces de la provocación que consiste en poner a cada comunidad frente a lo que ignora de la otra. Si esto «otro» puede ser leído por ésta o no, es otra cuestión, que depende de varios factores, generalmente imprevisibles. ${ }^{7}$ Lo que es seguro es que dentro de esta situación, responder a las solicitaciones de unos y otros produce una participación activa en mundos académicos e intelectuales distintos, que puede cuestionar los principios dominantes de cada uno de ellos, así como sus metodologías de trabajo.

Esta elección implica, por otro lado, una producción bilingüe abundante puesto que, si se quiere permanecer también dentro del hispanismo, es necesario seguir produciendo en español, o traducir y reescribir nuestros propios trabajos cuando tienen cierta importancia o cuando, una vez publicados en un idioma, interesan a la otra comunidad. Publicar y estar presente son, sin embargo, dos situaciones distintas; la presencia física sigue siendo necesaria para difundir nuestros escritos, en particular cuando se publica un libro; mi experiencia muestra que pasan prácticamente desapercibidos si no contamos con la posibilidad de estar presentes en el momento en que salen a la venta, o si no tenemos una presencia suficientemente sólida y constante en la comunidad de origen. Pienso que la elección de la lengua modifica el objeto mismo en su constitución y su alcance intelectual (en especial cuando somos bilingües), pero determina sólo en parte los lectores potenciales, porque cuando se circula entre especialistas de diferentes disciplinas es extremadamente difícil saber si somos leídos, y por quién, porque no existe en este caso un feedback disciplinario que nos permita medir el alcance de nuestros trabajos. Digamos que nuestros escritos derivan en comunidades y 
entre lectores que no encontramos más que de modo ocasional, y solamente el azar nos confronta al modo en que son leídos, porque quienes lo hacen no son los colegas que frecuentamos, y no necesariamente van a ponerse en contacto con nosotros para decirnos lo que piensan de nuestro trabajo. A veces el azar nos depara un encuentro con alguien que nos escuchó en un congreso o leyó uno de nuestros trabajos, y entonces tenemos la agradable sorpresa de enterarnos de que escritos que creíamos caídos en el olvido y el desinterés han sido leídos, comentados y usados; porque, en verdad, lo esencial no es tener lectores sino que lo que escribimos sea usado por otros para producir y para pensar.

El no pertenecer a la comunidad intelectual que organiza el evento (congreso, publicación), genera la impresión de una ausencia de recepción y nos coloca en una situación particular, solitaria pero también productiva; me toca seguido ser la literata entre sociólogos, historiadores, antropólogos, o especialistas de otras áreas, lo que siempre descoloca un poco. Circular entre comunidades intelectuales diferentes nos priva del sentimiento de pertenencia a una comunidad específica, y nos sitúa en una errancia disciplinaria. El revés de esta falta de pertenencia es la hostilidad que puede provocar nuestra circulación en otros ámbitos dentro de la comunidad a la que deberíamos pertenecer (lo que en este caso significa simplemente: la disciplina en la que hemos obtenido o podemos obtener una posición académica). Personalmente, cuando integré un centro de investigación no hispanista, no creía quemar las naves; si me dirigí a Jean-Marie Schaeffer y me integré en el CRAL (Centre de Recherchespour les Arts et le Langage, laboratorio CNRS-EHESS), fue porque acababa de terminar la primera parte de Borges ante el fascimo, aquella sobre los ensayos de Borges, y empezaba a trabajar las ficciones; por eso me dirigí a un especialista de la teoría de la ficción, esperando encontrar allí un diálogo que me ayudara a resolver las cuestiones intelectuales con las que me enfrentaba. Así fue, pero el resultado es que Borges ante el fascismo no es «ni chicha ni limonada»: no corresponde a la lectura dominante de Borges ni en el hispanismo internacional ni en la visión francesa; tampoco trabaja con la teoría de la ficción de la comunidad hispanista ni con la del CRAL. La situación es, sin embargo, más compleja que la que sugieren estas reflexiones, puesto que la circulación entre diferentes comunidades es aceptada cuando se trata de colegas que han alcanzado la jerarquía máxima institucional, a modo de reconocimiento de un especialista, pero resulta problemática para una disciplina en cuanto modo de producción. Las comunidades académicas demandan una fidelidad disciplinaria que mi errático modo de pensamiento y mi concepción del trabajo intelectual como espacio de libertad y de desafío permanente no permiten garantizar.

Podemos agregar que, en este caso, si el lector juega un papel en nuestros escritos es menos en cuanto receptor que en cuanto se inscribe en el modo de producción. En efecto, cuando circulamos en comunidades de no especialistas - por ejemplo entre comparatistas, o entre estudiosos de otras áreas culturales porque elegimos un eje transversal de trabajo y no uno temático específico a nuestra área cultural; o entre otras disciplinas, sociología, historia de las cien- 
cias, especialistas de literatura francesa, etc.- es necesario tomar una decisión previa: la de no considerar que es suficiente quedarse en el nivel de lo meramente informativo. En efecto, entre colegas no especialistas, todo lo que digamos puede constituir una novedad o un descubrimiento - y hay que confesar que a veces es un gran placer asistir a una exposición sobre un autor o una literatura que ignoramos enteramente aun cuando percibimos su carácter meramente informativo- Sin embargo, si queremos producir ensayos que nos permitan avanzar en nuestras reflexiones es necesario trabajar como si nos dirigiéramos a especialistas; pero para que un público no especializado entienda nuestros trabajos tenemos que rodearlos de una serie de precauciones que permitan seguir nuestro razonamiento, percibir el alcance de nuestras hipótesis, lo cual significa proporcionar los datos y toda información indispensable para ser escuchados por quienes ignoran el tema, sus bases y sus presupuestos. La tecnología moderna nos ayuda en este punto, porque es fácil proponer cronologías, armar power points con información, hacer y fotocopiar traducciones de textos, mostrar fotos, o proporcionar nuestro texto en dos idiomas; apoyar, entonces, nuestros trabajos en una serie de producciones que lleva tiempo y esfuerzo preparar, pero que permiten ir más allá de lo informativo, que proponen simultáneamente descubrir un objeto y postular una reflexión especializada. Así fue en el congreso en la Casa de Velázquez sobre «Literaturas y transiciones democráticas», en febrero del 20I5, donde éramos únicamente dos quienes hablamos de Argentina, en medio de colegas especialistas de India, Egipto, Francia, Espańa, Portugal, Argelia, Túnez, etc.; las dos versiones de mi texto (una en español y una en francés) se acompañaron de la traducción de varios fragmentos de Lenta biografía de Sergio Chejfec, de un power point con imágenes y documentación, y de una minuciosa cronología del período de la dictadura y los primeros diez ańos de democracia con todos los acontecimientos importantes. Este cuidado del que suelo rodear mis intervenciones busca facilitar la comprensión, pero también pone en evidencia mi convicción de que el hispanismo debería poder salir de su propio círculo y confrontarse a otros corpus y áreas culturales.

Esto permite decir que en estos casos producimos textos en los cuales se inscriben dos públicos: uno especializado, que no está necesariamente presente en la sala (aunque suele haber siempre al menos una persona especializada en nuestra área cultural, algún amigo o estudiante que generosamente nos viene a escuchar), y uno no especializado al que nos dirigimos (presente en cuerpo, en alma nunca se sabe). Estos escritos, ¿son un mero deseo? ¿Tienen realmente una recepción? El cruce puede, en todo caso, volverse un objeto productivo: allí donde dos tradiciones interpretativas entran en contacto puede elegirse adherir a una de ellas, y abandonar la otra — una actitud que el funcionamiento académico contemporáneo y la dinámica de las comunidades intelectuales especializadas favorece-; pero se puede hacer también la elección de volver productivo este cruce, aunque esto nos lleve a trabajos cuya recepción resulta problemática porque se alejan de las tendencias dominantes de cada comunidad. 
Son estos aspectos — la potencialidad y la productividad de las carreras construidas sobre dos frentes, un espacio no localizado en términos geográficos e institucionales, la innovación y la renovación que contienen estas situaciones - lo que quería señalar, antes de volver a otros menos positivos. Entre estos últimos mencionaré solamente dos: la asimetría de las relaciones y la temporalidad de la escritura.

En el caso de que nos ocupamos, la asimetría de las relaciones ha sido objeto de numerosas reflexiones desde el trabajo de Carl E. Pletsch, que propuso pensar el funcionamiento de las producciones científicas a partir de una división imaginaria entre las potencias centrales, que otorgarían al tercer mundo el rol de producir culturas destinadas a ser objeto de estudio de los etno-historiadores y de los antropólogos del Primer Mundo, quienes se encargarían de producir las teorías. ${ }^{8}$ En el ámbito de las producciones intelectuales hispanoamericanas, incluso cuando las teorías son producidas en el Primer Mundo, su dimensión teórica y metodológica no es necesariamente reconocida, lo que equivale a decir que su estatuto epistemológico sigue siendo el de objeto de estudio. ${ }^{9}$ Si en Estados Unidos la situación comienza a cambiar, ${ }^{10}$ no es seguro que sea el caso en Europa; en Francia, en todo caso, ninguno de los grandes clásicos de la crítica y de la teoría latinoamericana ha sido traducido aún. Pero la asimetría a que nos referimos es solamente en parte de orden lingüístico: los países hispanohablantes son grandes traductores y consumidores de trabajos intelectuales europeos y americanos, pero sus propias producciones son rara vez traducidas y exportadas $-\mathrm{y}$ cuando lo son (o cuando están escritas en la lengua del país) son poco leídas, y su circulación es restringida - Notemos también que las comunidades hispanoamericanas consideran (probablemente con razón) este desinterés en términos políticos.

En cuanto a la cuestión del ritmo de producción, que he tenido ocasión de evocar en otro artículo (2OI4), para los investigadores que llevamos adelante simultáneamente carreras en varias comunidades, insertándonos en ambientes académicos diferentes, en idiomas distintos, esto implica en parte, como dijimos, la necesidad de reescribir nuestros trabajos, lo cual demanda una inversión en tiempo y esfuerzo importante, que vuelve más lenta la progresión de las carreras y la difusión en cada una de las comunidades. Es verdad que en muchos casos se hace uno traducir, pero habría que interrogarse sobre estas prácticas, porque cuando un investigador bilingüe se hace traducir por otro, significa que considera que traducción equivale a reescritura. Sin embargo, todos los que han sido confrontados a esta situación saben que no es el caso: traducir a otro y traducirse a sí mismo son actividades radicalmente diferentes, que implican un trabajo con la lengua y con la relación con el público lector potencial muy distintos, porque los márgenes de libertad y de restricción se resignifican cuando uno se traduce a sí mismo. Trato generalmente de traducir mis propios libros y mis artículos cuando interesan a la otra comunidad, reescribiéndolos, porque pienso en públicos muy distintos; sin embargo, cuando reescribo del francés al español, es raro que agregue o modifique el texto porque los intelectuales argentinos están familiarizados con los autores y debates franceses. 


\section{Elegir un modo de inserción en la academia del país al que uno emigra signi-} fica entonces elegir un público, y producir una utopía crítica. El punto en que se cruzan potencialmente dos públicos es también un punto sin recepción, o de recepciones futuras, que dependen de inserciones, reconocimientos y modas intelectuales por venir. Todo esto para decir que en este caso no tenemos ni la menor idea de quiénes son nuestros lectores, aunque sí sepamos para quién escribimos.

\section{Notas}

${ }^{1}$ Agradezco a quienes leyeron versiones distintas de este trabajo, y lo mejoraron con sus lecturas generosas: Graciela Montaldo, Juan Pablo Dabove, Marcelo Topuzian y Jerónimo Ledesma.

${ }^{2}$ Son conocidas las polémicas alrededor de esta cuestión que siguieron la apertura democrática. Sobre el tema, ver también: Saúl Sosnowski y José Luis de Diego.

${ }^{3}$ No se trata aquí de una reflexión sobre la internacionalización de la producción científica, sino de pensar los desplazamientos, aunque es evidente que éstos contribuyen a la difusión internacional. Sería por supuesto interesante completar esta reflexión epistemológica con una encuesta.

4 Tomo la expresión de Manuel Puig, usada en relación con la escritura literaria: «Loss of readership».

${ }^{5}$ La Agregación es un concurso nacional que permite reclutar a los profesores del secundario en la escuela pública; este concurso no solamente garantiza un cargo en la enseñanza sino que permite la circulación entre diferentes puestos $y$, aunque no oficialmente, es necesario en algunas disciplinas para acceder a los puestos universitarios.

${ }^{6}$ El Capes (Certificat d'aptitude au professorat de l'enseignement du second degré) es un diploma profesional del Ministerio de educación nacional francés, que certifica la aptitud de enseñar en la secundaria y garantiza un puesto a este nivel; se prepara en dos años después de la Licenciatura (que en Francia dura tres años).

7 Personalmente fui confrontada a este problema cuando en mi laboratorio, el Centre de Recherches sur les Arts et le Langage, EHESS-CNRS, dirigido entonces por Jean-Marie Schaeffer, el equipo de literatura y narratología se interesó en la distinción entre relato ficcional y re- lato referencial; desde la producción literaria y la historia de la literatura argentina, la cuestión se presentaba bajo una luz totalmente distinta, y era incluso difícil comprender el esfuerzo de los teóricos franceses por discriminar entre ambos; para nosotros, resulta más interesante pensar los pasajes, en particular respecto de las expectativas del lector y de los pactos de lectura. Creo haber fracasado en mi intento por mostrar esto a mis colegas del centro, probablemente por falta de una posición institucional suficientemente prestigiosa, o tal vez porque me faltó la capacidad de teorizar el problema con suficiente rigor. Sobre el tema, ver Annick Louis, 20IOa y zoIob.

8 Pletsch propone una reflexión sobre los problemas que plantea la división en tres mundos nacida con la guerra fría; es interesante subrayar que aunque la división entre occidente y socialismo desapareció, y que la expresión «Tercer mundo» es menos usual, ciertos problemas señalados por Pletsch en relación con el comportamiento y con la ideología de las comunidades científicas permanecen, en particular la importancia adquirida por los estudios por áreas culturales, que él considera como una consecuencia de la división en tres mundos. Sobre esta cuestión puede verse también Sapiro.

${ }^{9}$ Algunos historiadores de las ciencias percibieron en este movimiento un eje constitutivo del saber moderno europeo: desde el siglo xviII, la reflexión filosófica fue representada en términos de una exploración física de territorios desconocidos, los científicos europeos como intrépidos viajeros cuyo saber era legitimado por sus exploraciones geográficas. El territorio lejano y desconocido proporcionaba la materia, Europa el saber mismo. Ver, en este sentido, "Heroic Narratives of Quest and Discovery» de Mary Terrall. 
10 A partir de los años 1990 , la voluntad explícita de entrar en diálogo con especialistas de otros campos hizo que una serie de críticos hispanoamericanos que trabajaban en universidades norteamericanas decidieran escribir en inglés, al tiempo que algunos de los clásicos de la producción intelectual de hispanoamérica eran traducidos, lo que les permitió circular en otras disciplinas, en particular gracias a la editorial de la Duke University Press y a la Pittsburgh University Press, cuyas colecciones valoran la dimensión teórica de estos trabajos, y se emancipan de las áreas culturales. $\mathrm{Al}$ mismo tiempo, lo que se denominaba «Tercer Mundo» ha sido vuelto a pensar a partir de categorías como «Subaltern Studies», «Cultural Studies», «Culturas híbridas», «Estudios post-coloniales» o «Transculturación».

\section{Bibliografía}

De Diego, José Luis (20I4). ¿Quién de nosotros escribirá el Facundo? Intelectuales y escritores en Argentina (1970-1986). Buenos Aires: Ediciones al Margen.

Louis, ANnick (20I0a). «Valeur littéraire et créativité critique». La valeur littéraire en question. París: L'Improviste, 33-55. (20Iob). «Sin pacto previo explícito. El caso de la autoficción», en Vera Toro, Sabine Schlickers, Ana Luengo, editoras. La obsesión del yo: la auto(r)ficción en la literatura española y latinoamericana. Madrid/Frankfurt: Iberoamericana/Vervuert, 73-96.

- (2014). «Lo que la encuesta hace a la disciplina literaria». El taco en la brea I [en línea]. Consultado el is de marzo de 2016 en www.dx.doi.org/Io.I4409/tb.viir.4215

Panesi, Jorge (2009). «Los que se van, los que se quedan: apunte para una historia de la crítica argentina». II Congreso Internacional Cuestiones Críticas. Rosario: Universidad Nacional de Rosario.

Pletsch, Carl E. (198I). "The Three Worlds, or the Division of Social Scientific Labor». Comparative Studies in Society and History 4, 565-590.

Puig, Manuel (1999). "Loss of readership». Revista Iberoamericana I87, 305-325.

SAPIRO, GIsèLE (Dir.) (2OI2). Traduire la littérature et les sciences humaines: conditions et obstacles. París: DEPS.

Sosnowski, SAÚl (Comp.) (1988). Represión y reconstrucción de una cultura: el caso argentino. Buenos Aires: Eudeba.

Terral, Mary (1998). «Heroic Narratives of Quest and Discovery». Configurations 6, 223-242. 